Proc. Indian Acad. Sci. (Earth Planet. Sci.), Vol. 94, No. 2, July 1985, pp. 129-137.

(C) Printed in India.

\title{
Monthly-mean wind stress along the coast of the north Indian Ocean
}

\author{
SATISH R SHETYE, S SATHEESH CHANDRA SHENOI, M K \\ ANTONY and V KRISHNA KUMAR \\ National Institute of Oceanography, Dona Paula, Goa 403004, India
}

MS received 17 April 1985

\begin{abstract}
Monthly-mean wind stress and its longshore and offshore components have been computed using the bulk aerodynamic method for each of a string of 36 two-degree-latitude by two-degree-longitude squares along the coast of the north Indian Ocean. The data source for the computation is the sixty-year mean resultant winds of Hastenrath and Lamb. The main features exhibited by the components, taking the longshore components as positive (negative) when the Ekman transport is away from (towards) the coast, are: (1) Along the coasts of Somalia and Arabia, the magnitude of the wind stress is among the highest in the north Indian Ocean, and its direction is generally parallel to the coastline. This results in a longshore component which is large (as high as $2.5 \mathrm{dyne} / \mathrm{cm}^{2}$ ) and positive during the southwest monsoon, and weaker (less than $0.6 \mathrm{dyne} / \mathrm{cm}^{2}$ ) and negative during the northeast monsoon. (2) Though weak (less than $0.2 \mathrm{dyne} / \mathrm{cm}^{2}$ ) during the northeast monsoon, the monthly-mean longshore component along the west coast of India remains positive throughout the year. The magnitude of the offshore component during the southwest monsoon is much larger than that of the longshore component. (3) The behaviour of the wind stress components along the east coast of India is similar to that along the Somalia-Arabia coast, but the magnitudes are much smaller.
\end{abstract}

Keywords. North Indian Ocean; coastal circulation; wind stress; upwelling; Ekman transport.

\section{Introduction}

Oceanographic studies in the coastal regions of the world have identified the stress exerted on the ocean surface by the local winds as one of the main forcing functions influencing the coastal processes. The importance of these winds in controlling the coastal dynamics was first brought out by the studies of Ekman (1905), Thorade (1909), and their contemporaries during the early part of this century. The present ideas on local wind-driven coastal currents have been summarized in Csanady (1982) among other references.

The north Indian Ocean is one of the very few oceanic regimes which come under the influence of the monsoons, and hence experiences a wind field which is very energetic at times and which possesses a well marked annual cycle. What controls the coastal processes in this ocean? An essential component of the answer to this many faceted question is the knowledge of the stress exerted by the winds in the vicinity of the coastline. With this consideration in mind, we have computed the montly-mean wind stress over the costal regime of the north Indian Ocean. The results are relevant to the study of the ocean's response on the time scale of a month or longer. Details on the method of computation, and on the computed stress field, can be found in Shetye et al (1984). Here we briefly summarize the main results. The next section describes the data 
base and the method followed for computing the wind stress. The main features of the stress field and its longshore and offshore components are presented in $\$ 3$.

\section{Data source and method of computation}

Hasternrath and Lamb (1978) give sixty-year (1911-1970) monthly mean climate and circulation over the Indian Ocean. Charts $14-25$ in their atlas give the resultant wind on a $1^{\circ}$-latitude by $1^{\circ}$-longitude grid. These form the basic data for our computations. To determine the pattern of the coastal wind stress field we chose a string of 36 squares, each $2^{\circ}$-latitude by $2^{\circ}$-longitude, along the coast of the north Indian Ocean. We shall refer to each of these squares as a TDS, meaning a two-degree-square. Wind stress has been computed for each TDs for each month of the year.

To understand the influence of wind stress on coastal processes, it is convenient to express the stress in terms of the longshore and the offshore component. For computing these, the orientation of the coastline needs to be defined. As the scale of resolution for determining the wind stress has been chosen to be $\left(2^{\circ} \times 2^{\circ}\right)$, it may suffice to determine the mean orientation of the coastline for each TDs. There is, however, some ambiguity in defining the orientation of a coastline. It could be defined as a line where the mean depth approaches zero, or as the line of the continental shelf break. The influence of the bottom topography on shelf circulation is not known in detail sufficient to choose between either of these two possibilities. Along the coast of India the shelf break occurs approximately at the $200 \mathrm{~m}$ isobath. On moving offshore from this isobath the depth increases rapidly from $200 \mathrm{~m}$ to more than $2000 \mathrm{~m}$. In the present discussion we take the $200 \mathrm{~m}$ isobath as the indicator of the "coastline". Fortunately, the subjectivity in the choice of the coastline orientation is not a source of serious discrepancy; at least, not for a large fraction of the coastline. This is because the $200 \mathrm{~m}$ isobath runs more or less parallel to the zero-meter isobath along most of the coast. A notable exception is the region immediately to the south of Sourashtra. The configuration of the 36 TDs has been chosen such that, firstly, the $200 \mathrm{~m}$ isobath in the north Indian Ocean is adequately covered, and secondly, wind stress computed for each TDS is representative for an area upto an offshore distance of an internal radius of deformation from the $200 \mathrm{~m}$ isobath. To compute the longshore and the offshore component the $200 \mathrm{~m}$ isobath was idealised by a straight line for each TDs. The 36 TDS and the idealised $200 \mathrm{~m}$ isobath are shown in figure 1.

The stress field has been computed by using the well known bulk aerodynamical formula

$$
\tau=\rho_{a} C_{D} V^{2} \text {. }
$$

$\tau$ is the magnitude of the wind stress $\left(\mathrm{Newton} / \mathrm{m}^{2}\right), \rho_{a}$ is the density of the air $\left(1.175 \mathrm{~kg} / \mathrm{m}^{3}\right)$ and $C_{D}$ is the dimensionless drag coefficient. The direction of the wind stress was taken to be the same as the direction of the monthly-mean resultant wind for a TDS. There has been extensive discussion on the choice of a value for $C_{D}$ (see, for example, Bunker 1976). Suggested values range between a low of $0.7 \times 10^{-3}$ for low wind speeds and a high approaching $4 \times 10^{-3}$ for high winds. Here we use a constant value of $1.3 \times 10^{-3}$ because it has been found appropriate in earlier investigations of coastal regions (see, for example, Prell and Streeter (1982)). Figure 2 summarizes the annual cycle of the computed stress field. 


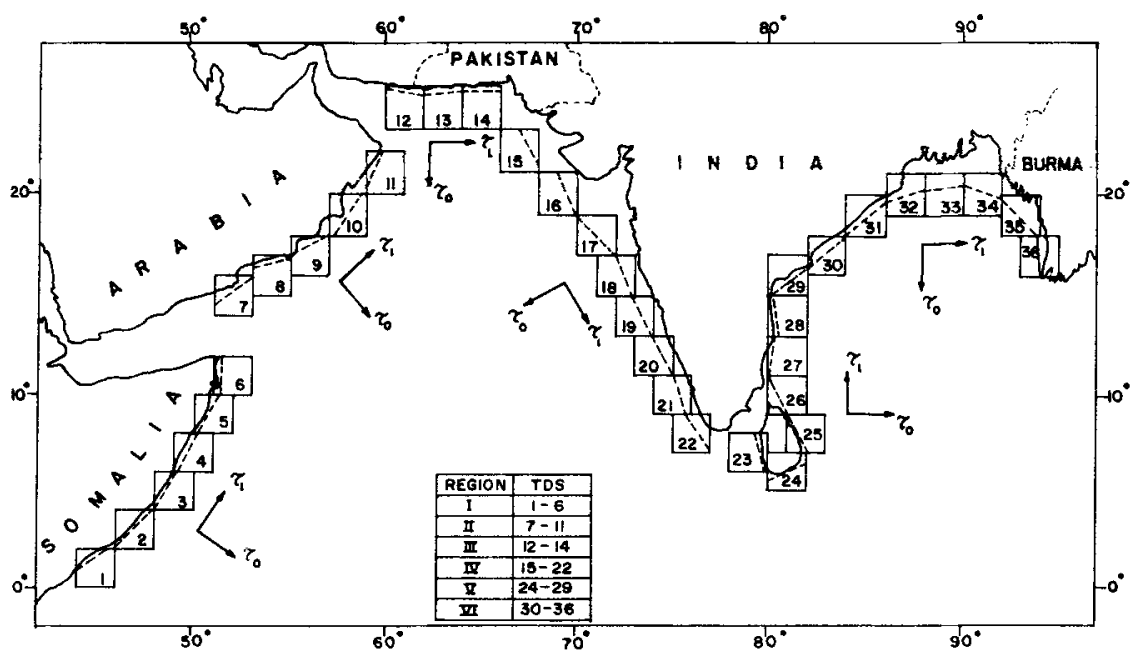

Figure 1. The region of interest. The dashed line shows the idealized geometry of the $200 \mathrm{~m}$ isobath. Each of the numbered squares is two-degree-latitude by two-degree-longitude. The grouping of the two-degree-squares, for plotting the longshore and the offshore component in figures 3 and 4, is as follows: the two-degree-squares $1-6,7-11,12-14,15-22,24-29$, and 30-36 form regions I, II, III, IV, V and VI respectively. Approximate orientation of $\left(\tau_{l}, \tau_{o}\right)$ frame for each region is also shown.

To compute the longshore $\left(\tau_{l}\right)$ and the offshore $\left(\tau_{o}\right)$ component, the stress vector for each TDS was decomposed along the tangent and the normal to the straight line idealizing the $200 \mathrm{~m}$ isobath for that TDS. The $\left(\tau_{l}, \tau_{o}\right)$ reference frame was chosen such that for a positive longshore component the Ekman transport would be away from the coast. Once the direction of positive longshore component is defined, the cross-shore positive direction is fixed at right angle in the clockwise direction. To summarize the annual cycle of $\tau_{l}$ and of $\tau_{0}$ we divided the 36 TDs into regions I to V. Each region covers

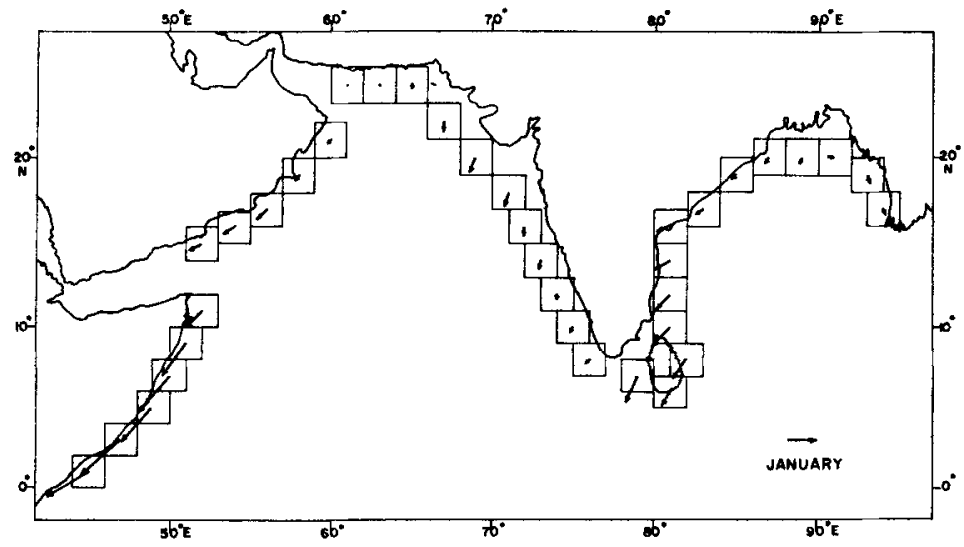

Figure 2. 

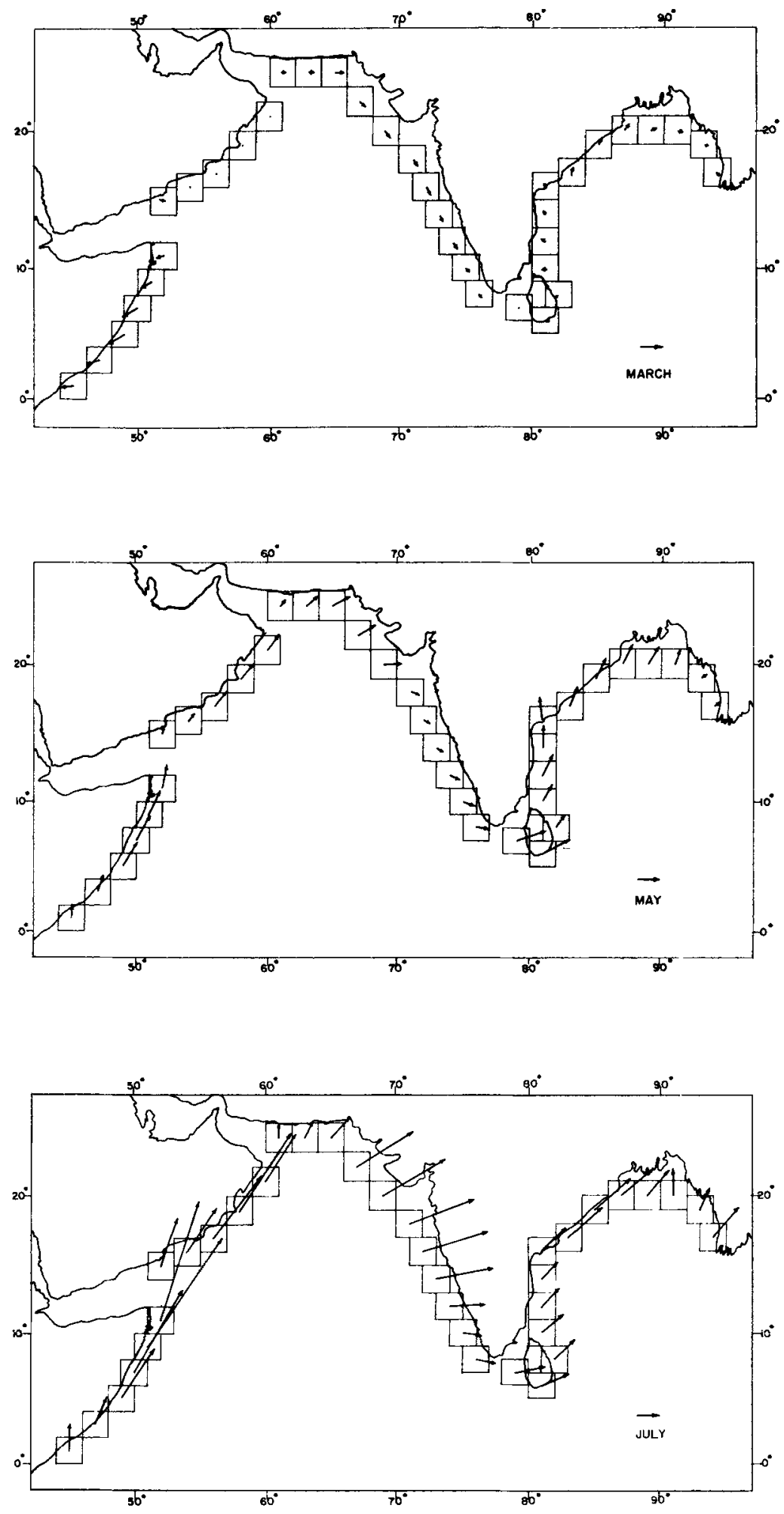

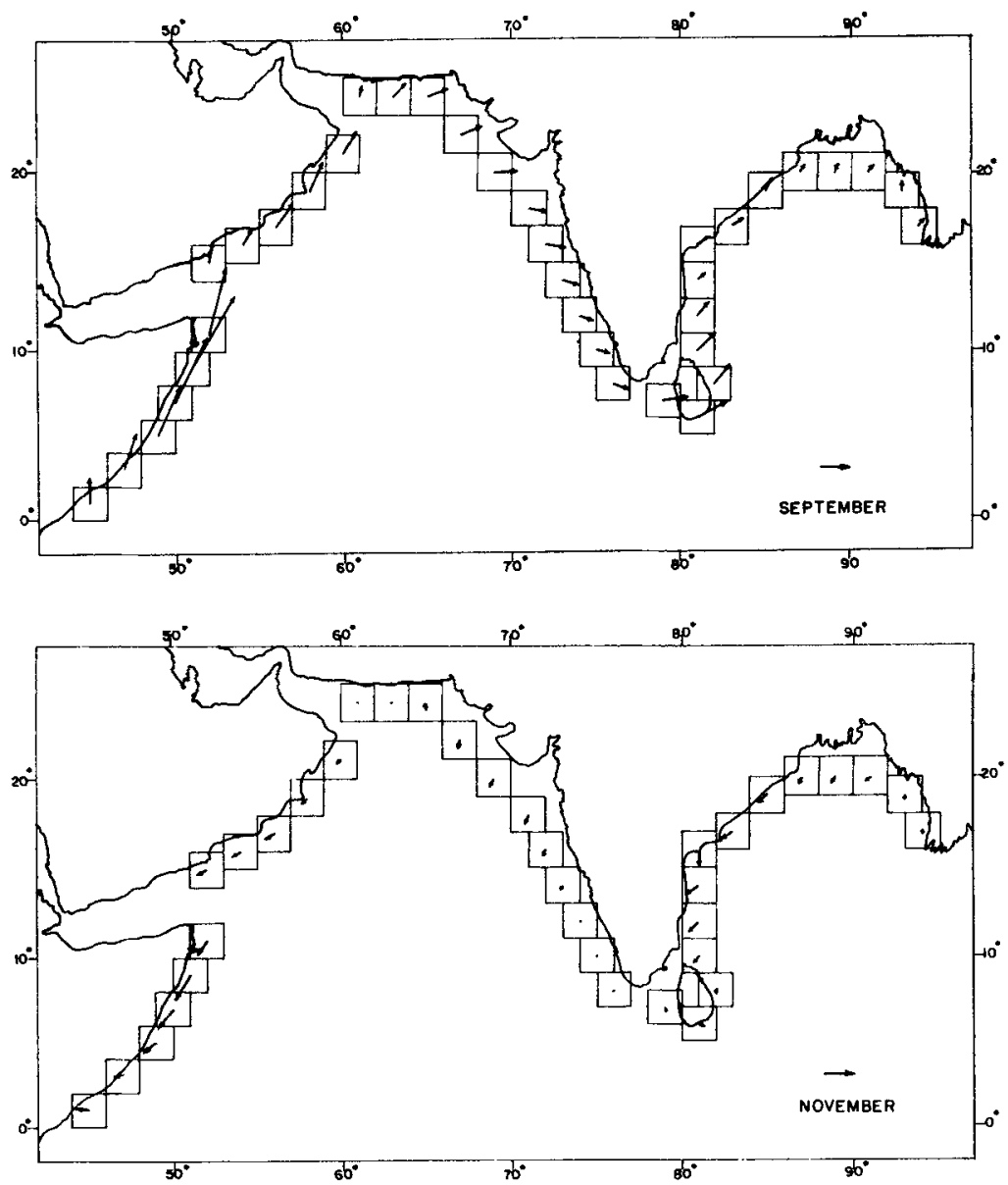

Figure 2. Monthly-mean wind stress for each two-degree square. The month is shown in the lower right hand corner. The magnitude of the arrow shown just above the month is $0.5 \mathrm{dyne} / \mathrm{cm}^{2}$. The arrow for a two-degree-square has been drawn such that its origin is at the center of the square; the arrowhead points in the direction of the stress. Whenever the magnitude of the stress is equal to or less than $0.05 \mathrm{dyne} / \mathrm{cm}^{2}$, only a dot has been shown at the center of the square.

an approximately straight portion of the coastline. The TDs belonging to each region are defined in figure 1 . The annual cycle of $\tau_{l}$ and that of $\tau_{o}$ is summarized in figures 3 and 4 respectively.

\section{Results and discussion}

The winds over the north Indian Ocean are dominated by the monsoon circulation. During November through February the winds blow predominantly from the northeast; during May through September they blow from the southwest. Though these two are the mean directions for the two seasons for the monsoon area as a whole, 


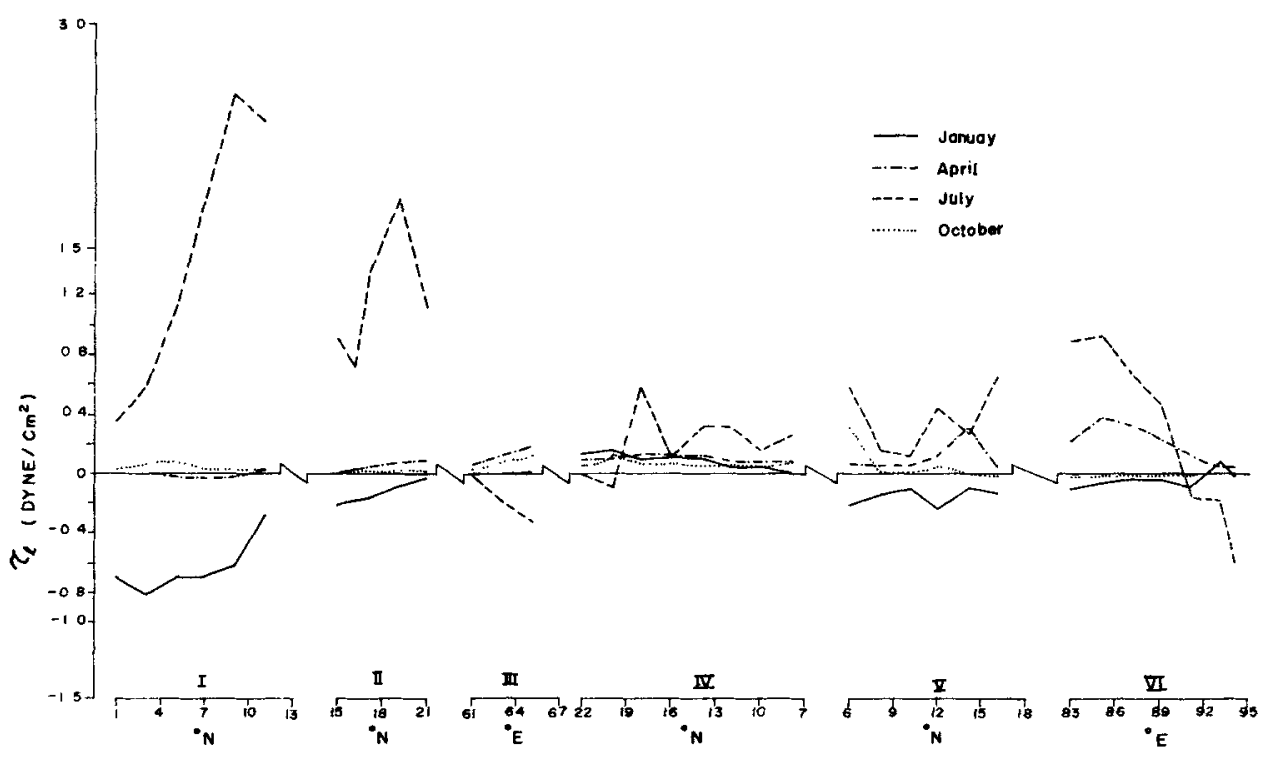

Figure 3. Spatial variation of the longshore component $\left(\tau_{1}\right)$ during January, April, July and October. The Roman numbers (I to VI) refer to regions defined in figure 1, which also shows the orientation of the $\left(\tau_{l}, \tau_{o}\right)$ frame for each region.

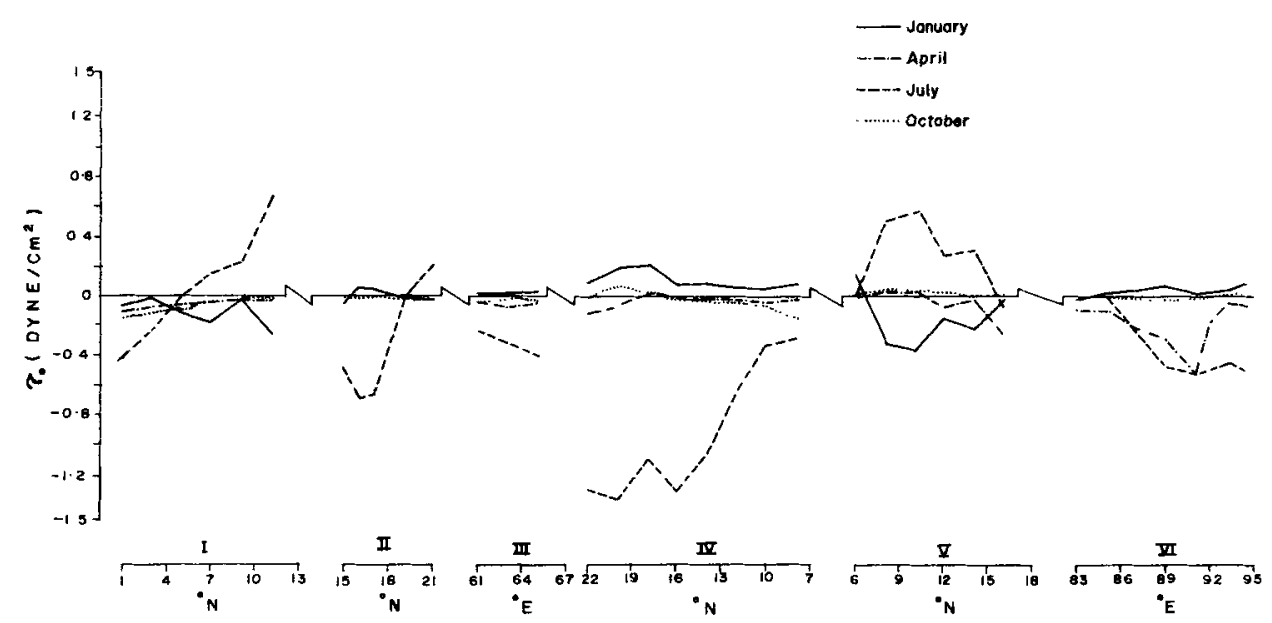

Figure 4. Spatial variation of the offshore component $\left(\tau_{o}\right)$ during January, April, July and October. See caption to figure 3 for other details.

significant variations in the orientation of the winds from these directions are seen from location to location. For example, over the southwest coast of India the winds during the southwest monsoon are more or less westerly. It is the combination of the local wind stress direction, and the orientation of the coastline, that determines the nature of variation of $\left(\tau_{l}, \tau_{o}\right)$ along the coastline.

Winds off Somalia and Arabia are among the largest in the region of interest, and stay more or less parallel to the coastline throughout the year. As a result, the magnitude of 
$\tau_{l}$ stays quite large in comparison to $\tau_{0} . \tau_{l}$ is positive and reaches a peak $\left(2.5 \mathrm{dyne} / \mathrm{cm}^{2}\right)$ at around $9 \mathrm{~N}$ in the month of July. Very high upwelling rates have been reported in this area during this month (see, Duing and Leetmaa 1980). During the northeast monsoon the longshore component off this coast is negative. However, its peak magnitude is almost one-fourth of the peak longshore component during the southwest monsoon.

The west coast of India poses a contrast to the Somalia-Arabia region. The longshore component along the west coast remains positive throughout the year. It reaches a peak $\left(0.5 \mathrm{dyne} / \mathrm{cm}^{2}\right)$ around July; between November and February this component is quite weak $\left(<0.1 \mathrm{dyne} / \mathrm{cm}^{2}\right.$ ). Another interesting feature of this coast is that the magnitude of the offshore component is generally much larger than the longshore component. Along the east coast of India the longshore component reverses sign; it is positive during the southwest monsoon season and negative during northeast season. The temporal variability of the stress is similar to that along the Somalia and the Arabia coastline. However, the magnitude of the stress along the east coast of India is much smaller than that in the western Arabian sea.

The offshore Ekman transport due to local winds is given by

$$
M_{E}=\tau_{l} / f
$$
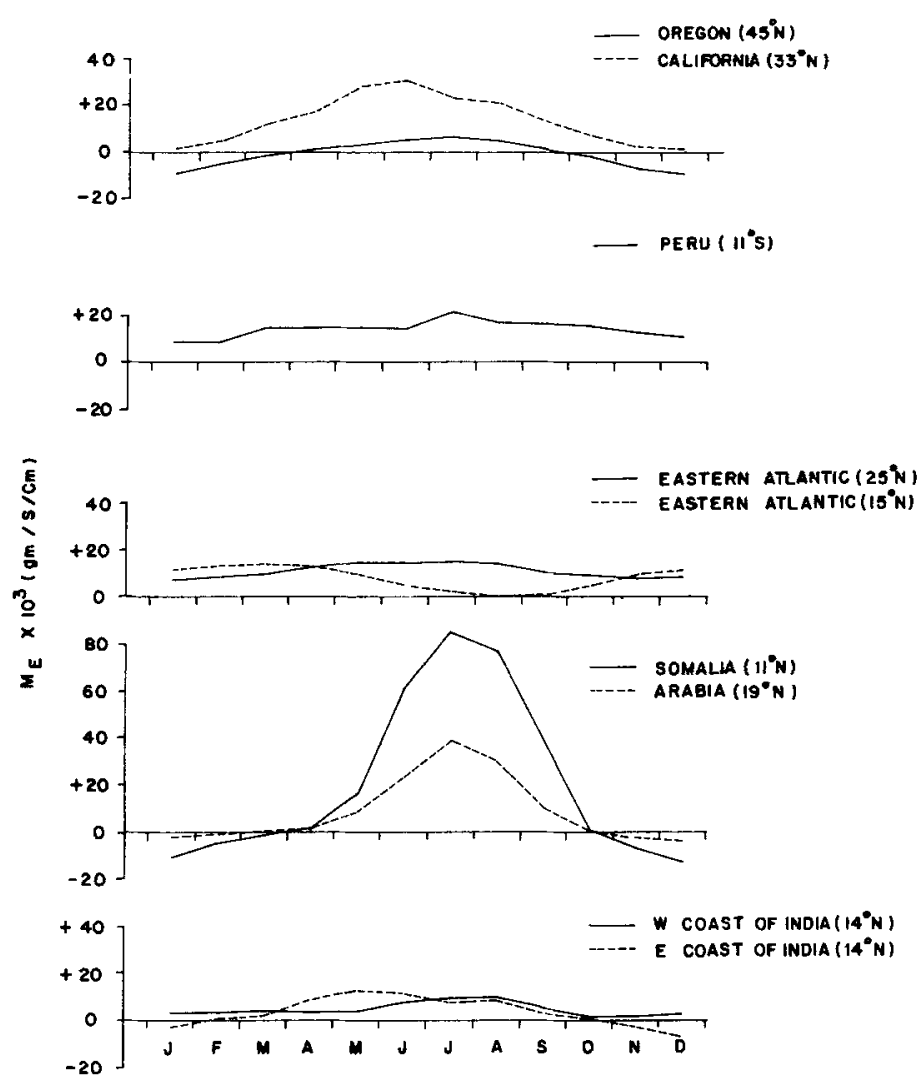

Figure 5. A comparison of the annual march of the offshore Ekman transport $\left(M_{E} \mathrm{gm} / \mathrm{s} / \mathrm{cm}\right)$ at a few coastal locations around the world. 
where $f$ is the Coriolis parameter. $M_{E}$ is an indicator of the potential for upwelling in the coastal areas where the local winds form the dominant forcing function for the coastal processes (see Wooster and Reid 1963). It is of interest to compare the variation of $M_{E}$ at a few locations in the north Indian Ocean with $M_{E}$ at some of the better known upwelling centres of the world. This has been done in figure 5 . The data for the coastal regions of California (33 N) and Oregon (45 N) are taken from Bakun (1973). Wyrtki and Meyers (1975) estimate of wind stress in the Pacific was used for computing the longshore component off Peru (10-12 S). The data for the eastern N. Atlantic are based on Wooster et al (1976). TDS $6(10-12 \mathrm{~N})$ and $10(18-20 \mathrm{~N})$ were used to represent the coast of Somalia and Arabia respectively. TDs 19 (13-15 N, west coast of India) and 28 (13-15 N, east coast of India) represent the west and the east coast of India. The drag coefficient $C_{b}$ was put equal to $1.3 \times 10^{-3}$ in all computations. As seen from figure 5 , the monthly-mean wind stress in the coastal regions of California, Peru, eastern north Atlantic and the west coast of India is conducive to upwelling throughout the year. This is in contrast to the conditions off Oregon, Arabia, Somalia and the east coast of India, where the longshore component changes sign. At these locations, the winds are favourable to upwelling only between April and October. The amplitude of the annual cycle of the longshore component is larger off Oregon than that off the east coast of India. Coasts of California, Somalia and Arabia are conspicuous for the large longshore wind stress they experience.

To use $M_{E}$ as an indicator of the potential for upwelling it must first be established that the local winds provide the dominant forcing for the coastal processes. There has been little discussion so far on the question of the dominant forcing functions for the circulation along the coast of the north Indian Ocean. A notable exception is the coast of Somalia (see for example, Lighthill 1969 and Anderson and Rowland 1976). In a forthcoming study we shall examine the extent to which the monthly-mean coastal circulation in the north Indian Ocean can be attributed to the wind stress field described in the present paper.

\section{Acknowledgements}

During the course of this study one of the authors (S. R. S) was supported by a N.I.O. Research Associateship. Director, N.I.O. made the necessary facilities available during the preparation of the study. This paper has benefitted from the comments of Drs. J S Sastry and C S Murty. Ravindranath Uchil drafted the figures.

\section{References}

Anderson D L T and Rowland P B 1976 J. Mar. Res. 34395

Bakun A 1973 nOAA Technical report NMFS SSRF-671, U.S. Department of commerce.

Bunker A F 1976 Mon. Weather Rev. 1041122

Csanady G T 1982 Circulation in the coastal ocean. (Dordrecht; D. Reidel)

Duing W and Leetmaa A 1980 J. Phys. Oceanogr. 10307

Ekman V 1905 Ark. f. Mat. Antr. Och. Fysik. k. Sv. Vet. Ak., Stockholm, 2

Hastenrath S and Lamb P J 1978 Climatic atlas of the Indian Ocean, Part 1: Surface Climate and Atmospheric Circulation. (Madison; University of Winconsin Press.)

Lighthill M J 1969 Philos. Trans. R. Soc. Lond. A265 45 
Prell W L and Streeter H F 1982 J. Mar. Res. 40143

Shetye S, Shenoi S S C, Antony M K and Kumar V K 1984 Tectinical Report, National Institute of Oceanography, Goa.

Thorade H 1909 Aun. d. Hydrogr. U. Mar. Meteor. 3717

Wooster W S and Reid J L 1963 The Sea (ed) M N Hill (New York: Interscience) Vol 2 p. 253

Wooster W S, Bakun A and McLain D 1976 J. Mar. Res. 34131

Wyrtki K and Meyers G 1975 Technical Report, Hawaii Institute of Geophysics. 